Review Article

\title{
Can We Identify or Exclude Extensive Axillary Nodal Involvement in Breast Cancer Patients Preoperatively?
}

\author{
Martijn Leenders ${ }^{D}$, ${ }^{1}$ Gaëlle Kramer, ${ }^{1}$ Kamar Belghazi, ${ }^{1}$ Katya Duvivier, ${ }^{2}$ \\ Petrousjka van den Tol, ${ }^{3}$ and Hermien Schreurs ${ }^{1}$ \\ ${ }^{1}$ Department of Surgery, Northwest Clinics, Wilhelminalaan 12, 1815 JD Alkmaar, Netherlands \\ ${ }^{2}$ Department of Radiology, VU Medical Centre, De Boelelaan 1117, $1081 \mathrm{HV}$ Amsterdam, Netherlands \\ ${ }^{3}$ Department of Surgery, VU Medical Centre, De Boelelaan 1117, 1081 HV Amsterdam, Netherlands
}

Correspondence should be addressed to Martijn Leenders; martijn_leenders@hotmail.com

Received 5 January 2019; Revised 23 September 2019; Accepted 8 October 2019; Published 22 November 2019

Guest Editor: Theodoros N. Sergentanis

Copyright (c) 2019 Martijn Leenders et al. This is an open access article distributed under the Creative Commons Attribution License, which permits unrestricted use, distribution, and reproduction in any medium, provided the original work is properly cited.

\begin{abstract}
Background. Breast cancer treatment has rapidly changed in the last few years. Particularly, treatment of patients with axillary nodal involvement has evolved after publication of several randomized clinical trials. Omitting axillary lymph node dissection in selected early breast cancer patients with one or two positive sentinel nodes did not compromise overall survival nor regional disease control in these trials. Hence, either excluding or identifying extensive axillary nodal involvement becomes increasingly important. Purpose. To evaluate whether the current diagnostic modalities can accurately identify or exclude extensive axillary nodal involvement. Evaluated modalities were axillary ultrasound, ultrasound-guided needle biopsy, MRI, and PET/CT. Methods. A literature search was performed in the Cochrane Library, EMBASE, and PubMed databases up to June 2019. The search strategy included terms for breast cancer, lymph nodes, and the different imaging modalities. Only articles that reported pathological $N$ stage or the total number of positive axillary lymph nodes were considered for inclusion. Studies with patients undergoing neoadjuvant systemic therapy were excluded. Conclusion. There is no evidence that any of the current preoperative axillary imaging modalities can accurately exclude or identify breast cancer patients with extensive nodal involvement. Both negative PET/ CT and negative MRI scans (with gadolinium-based contrast agents) are promising in excluding extensive nodal involvement. Larger studies should be performed to strengthen this conclusion. False-negative rates of axillary ultrasound and ultrasoundguided needle biopsy are too high to rely on negative results of these modalities in excluding extensive nodal involvement.
\end{abstract}

\section{Introduction}

Since the first radical mastectomy by Halsted in the late 1800s, breast cancer surgery has become much less mutilating. Currently, results of breast-conserving surgery are excellent, due to early detection by breast cancer screening programs and the application of (neo)adjuvant treatment modalities. Axillary treatment is rapidly evolving as well. The results of the ACOSOG Z0011 [1], IBCSG 23-01 [2], and AATRM 048/13/2000 [3] trials demonstrated that selected breast cancer patients with one or two positive sentinel nodes do not benefit from completion ALND (cALND) in terms of local control, disease-free survival, and overall survival [1-3]. In these trials, only clinical T1-2N0 patients undergoing breast-conserving surgery followed by whole breast irradiation and systemic therapy were included. Therefore, most national guidelines now recommend avoiding cALND in breast cancer patients with one or two positive sentinel nodes who meet these eligibility criteria. Hence, the outcome of the sentinel node biopsy (SNB) in this subgroup of patients has actually no clinical consequences. Consequently, randomized clinical trials are recently initiated to study whether SNB can be safely omitted in these patients (SOUND [4], BOOG 2013-08 [5], and INSEMA). However, the presence of extensive nodal involvement should still be excluded. Patients with extensive nodal 
involvement do not meet the eligibility criteria of the ACOSOG Z0011 trial and should therefore receive axillary treatment according to the recent guidelines. Ideally, this presence of extensive nodal involvement is accurately excluded by negative results of preoperative axillary imaging modalities. Patients with extensive axillary nodal involvement are at a much higher risk for locoregional recurrence. Irradiation of regional lymph nodes is therefore advised in these patients since it improves prognosis [6-8]. Identifying extensive nodal involvement is thus an important selection factor for postoperative regional radiotherapy. Neoadjuvant systemic therapy is increasingly implemented in patients with node-positive disease. Hence, the number of positive nodes is preferably estimated by a noninvasive axillary imaging modality before the start of neoadjuvant systemic therapy.

The first aim of this review was to evaluate whether negative results of the current preoperative axillary imaging modalities can exclude extensive nodal involvement in newly diagnosed breast cancer patients. Modalities that were evaluated are axillary ultrasound (AxUS), ultrasound-guided needle biopsy (UNB), magnetic resonance imaging (MRI), and fluorine-18-fluoro-2-deoxy-D-glucose positron emission tomography/computed tomography (PET/CT). The second aim of this review was to evaluate whether these diagnostic modalities can distinguish breast cancer patients with extensive axillary nodal involvement from patients with no or limited nodal involvement.

\section{Methods}

A literature search was performed in the Cochrane Library, EMBASE, and PubMed databases up to June 2019. Filters used were English language and human studies. The search strategy included terms for breast cancer, lymph nodes, and the different diagnostic entities (AxUS, UNB, MRI, and $\mathrm{PET} / \mathrm{CT}$ ). The inclusion criteria were as follows: (1) newly diagnosed, histologically proven breast cancer patients, (2) the diagnostic modality was performed preoperatively, (3) node histology (based on SNB and/or ALND) was the reference standard for ascertaining presence/absence of metastatic nodes, (4) cALND was performed in case of a positive sentinel node, and (5) pathological $N$-stage or total number of positive nodes was reported. Exclusion criteria were (1) studies with patients undergoing neoadjuvant systemic therapy.

To determine whether negative results of preoperative axillary imaging modalities can exclude extensive nodal involvement, both negative predictive values (NPVs) and false-negative rates (FNRs) were calculated from the raw data of all included studies. For this purpose, NPV is defined as the proportion of patients with a negative test result that does not have extensive nodal involvement histologically (i.e., number of patients with a negative test result who did not have extensive nodal involvement histologically/number of patients with a negative test result). FNR is defined as the proportion of patients with extensive nodal involvement which yielded a negative test result (i.e., number of patients with extensive nodal involvement and a negative test result/ number of patients with extensive nodal involvement). The combination of NPV and FNR was used to determine which diagnostic entity is the optimal test to exclude extensive nodal involvement.

To evaluate whether preoperative axillary imaging modalities can accurately distinguish patients with no or limited axillary nodal involvement from patients with extensive nodal involvement, we evaluated studies that were specifically designed for this purpose.

Currently, there is some ambiguity on the definition of extensive nodal involvement. The ACOSOG Z0011 trial defined extensive nodal involvement as $\geq 3$ positive nodes. However, according to TNM classification, extensive nodal involvement is defined as $\geq 4$ histologically positive nodes (pN2-3). In this review, we will quantify the number of positive nodes whenever needed to avoid ambiguity.

\section{Results}

\subsection{Axillary Ultrasonography}

3.1.1. Excluding Extensive Nodal Involvement. A number of studies on accuracy of AxUS described the total number of histologically positive nodes. In Table 1, all studies that included at least 200 patients are summarized. In studies that defined extensive nodal involvement as pN2-3 (that is $\geq 4$ positive nodes), the FNR ranges from 10 to $50 \%$ (mean $18 \%$ ). Thus, on average, $18 \%$ of patients with extensive nodal involvement had a normal AxUS. The NPV of a normal AxUS to exclude extensive nodal involvement ranges from 92 to $97 \%$ (mean 96\%) in these studies [9-15]. In studies that defined extensive nodal involvement as $\geq 3$ positive nodes, the FNR ranges from 30 to $37 \%$ (mean 34\%). NPV in these studies ranges from 92 to $98 \%$ (mean 95\%) (Table 1) [16-23].

\subsubsection{Identifying Patients with Extensive Nodal Involvement.} In the post-ACOSOG Z0011 era, several studies examined whether AxUS could be used to distinguish between limited and extensive axillary nodal involvement. Most studies focused on the association between the number of sonographically suspicious nodes and the extent of (pathological) nodal disease. These studies concluded that the mean number of positive axillary nodes is significantly higher amongst patients with their positive nodes identified by AxUS than by SNB $[14,19,24]$. Further, the presence of extensive nodal involvement is significantly associated with the number of sonographically suspicious nodes in these studies [12, 17, 18, 21, 25-31]. For instance, Kim et al. [18] showed that the percentage of patients with $\geq 3$ positive nodes was $3.1 \%$ vs. $38.5 \%$ vs. $62.5 \%$ in case of $\leq 1,2$, or $\geq 3$ sonographically suspicious nodes $(P<0.001)$. In multivariate analysis, the odds ratios for $\geq 3$ positive nodes were significantly increased when two suspicious nodes were seen (OR 6.52, 95\% CI 1.36-31.28) and when more than two suspicious nodes were seen (OR 21.08, 95\% CI 2.57-172.86) [18]. Farrell et al. [25] showed that the mean number of histologically positive nodes was significantly higher if more than two suspicious nodes were detected sonographically compared to two or only one (10.1 vs. 7.5 vs. 5.2) [25]. 
TABLE 1: Summary of studies on axillary ultrasonography to exclude patients with extensive nodal involvement.

\begin{tabular}{|c|c|c|c|c|c|c|c|}
\hline Study & Year & $\begin{array}{l}\text { No. of } \\
\text { patients }\end{array}$ & $\begin{array}{l}\text { No. (\%) of patients with extensive nodal } \\
\text { involvement }\end{array}$ & $\begin{array}{l}\text { No. of false } \\
\text { negatives }\end{array}$ & $\begin{array}{l}\text { No. of true } \\
\text { negatives }\end{array}$ & $\begin{array}{c}\text { NPV } \\
(\%)\end{array}$ & $\begin{array}{c}\text { FNR } \\
(\%)\end{array}$ \\
\hline \multicolumn{8}{|c|}{ Studies in which extensive nodal involvement was defined as pN2-3 } \\
\hline Abe et al. [9] & 2013 & 559 & $60(10.7 \%)$ & 10 & 368 & 97 & 17 \\
\hline $\begin{array}{l}\text { Amonkar et al. } \\
{[10]}\end{array}$ & 2013 & 439 & $44(10.0 \%)$ & 10 & 283 & 97 & 23 \\
\hline $\begin{array}{l}\text { Jackson et al. } \\
{[11]}\end{array}$ & 2015 & 494 & $48(9.7 \%)$ & 14 & 369 & 96 & 29 \\
\hline Kijima et al. [12] & 2010 & 380 & $67(17.6 \%)$ & 10 & 238 & 96 & 15 \\
\hline Liu et al. [13] & 2018 & 3944 & $664(16.8 \%)$ & 64 & 2236 & 97 & 10 \\
\hline $\begin{array}{l}\text { Wely van et al. } \\
{[14]}\end{array}$ & 2013 & 1448 & $178(12.3 \%)$ & 89 & 1094 & 92 & 50 \\
\hline Zhang et al. [15] & 2015 & 1049 & $207(19.7 \%)$ & 33 & 619 & 95 & 16 \\
\hline Mean & & & & & & 96 & 18 \\
\hline \multicolumn{8}{|c|}{ Studies in which extensive nodal involvement was defined as $\geq 3$ positive nodes } \\
\hline Barco et al. [16] & 2016 & 1533 & $210(13.7 \%)$ & 64 & 1127 & 95 & 30 \\
\hline $\begin{array}{l}\text { Hieken et al. } \\
{[17]}\end{array}$ & 2013 & 906 & $76(8.4 \%)$ & 23 & 620 & 96 & 30 \\
\hline Kim et al. [18] & 2019 & 311 & $19(6.1 \%)$ & 6 & 238 & 98 & 32 \\
\hline $\begin{array}{l}\text { Kramer et al. } \\
{[19]}\end{array}$ & 2016 & 2130 & $248(11.6 \%)$ & 91 & 1491 & 94 & 37 \\
\hline Lee et al. [20] & 2013 & 210 & 38 (18.1\%) & 12 & 130 & 92 & 32 \\
\hline Lim et al. [21] & 2019 & 1298 & $180(13.9 \%)$ & 62 & 950 & 94 & 34 \\
\hline $\begin{array}{l}\text { Moorman et al. } \\
{[22]}\end{array}$ & 2014 & 1060 & $102(9.6 \%)$ & 37 & 842 & 96 & 36 \\
\hline $\begin{array}{l}\text { Morrow et al. } \\
{[23]}\end{array}$ & 2018 & 4695 & $594(12.7 \%)$ & 206 & 3374 & 94 & 35 \\
\hline Mean & & & & & & 95 & 34 \\
\hline
\end{tabular}

AxUS = axillary ultrasonography; no. of false negatives = number of patients with normal/negative AxUS but histologically extensive nodal involvement; no. of true negatives $=$ number of patients with normal/negative AxUS and histologically no/limited nodal involvement; NPV= negative predictive value; $\mathrm{FNR}=$ false-negative rate.

Studies differentiating between $\mathrm{cN} 0, \mathrm{cN} 1$, and $\mathrm{cN} 2-3$ disease (based on sonographic number of suspicious axillary nodes) also showed that the percentage of patients with $\mathrm{pN} 2-3$ disease was significantly higher in case of cN1 or cN2-3 disease compared to $\mathrm{cN} 0$ disease $[12,26,27]$. In patients who were sonographically classified as cN2-3, the percentage of patients with pN2-3 disease was very high, that is, $100 \%$ ( 2 of 2) [27], $100 \%$ (2 of 2) [26], and $84 \%$ (46 of 55) [12], respectively. However, when using this threshold of $\mathrm{cN} 2-3$, a lot of patients with pN2-3 were missed since the FNR was $87.5 \%$ [27], 95.7\% [26], and 31.3\% [12], respectively. In short, the extent of nodal involvement is significantly associated with the number of sonographically suspicious nodes. The most optimal cutoff to distinguish between limited and extensive nodal involvement has not been determined yet.

Several studies examined the association between maximum cortical thickness of the most suspicious node and the extent of nodal involvement. All studies concluded that increased cortical thickness was an independent predictor of extensive nodal involvement $[10,18,28,32,33]$. The most optimal cutoff value to discriminate between limited and extensive nodal involvement ranges between 3.0 and 5.0 millimeters in these studies [10, 18, 28]. For instance, Lim et al. [33] used a cutoff point of maximum cortical thickness of 4.0 millimeters. When maximum cortical thickness was larger than 4.0 millimeters, PPV to predict $\geq 3$ positive nodes was $82.5 \%(33 / 40)$. However, the FNR at this cutoff was $68.6 \%$ (72/
105). Hence, the majority of patients with $\geq 3$ positive nodes were missed when using this cutoff point [33].

One study used a combination of morphology of suspicious nodes and number of sonographically suspicious nodes to predict pN2-3 disease [9]. In this study, one experienced radiologist retrospectively reviewed AxUS images of 559 patients and determined whether there were any suspicious nodes. The suspicious nodes were categorized with a grade of suspicion of high (complete or near-complete absence of fatty hilum), medium (cortical thickness $>4 \mathrm{~mm}$ or asymmetrical cortical thickening $>3 \mathrm{~mm}$ ), or low (uniform cortical thickening of 3-4 mm). They reported that $\mathrm{pN} 2-3$ disease was highly likely (PPV of $82 \%$ ) when there were at least two lymph nodes of high suspicion. By using this cutoff, many patients with pN2-3 disease were missed because sensitivity of predicting pN2-3 disease was only 54\% [9].

\subsection{Ultrasound-Guided Needle Biopsy}

3.2.1. Excluding Extensive Nodal Involvement. In Table 2, we listed all studies on accuracy of AxUS followed by ultrasoundguided needle biopsy of a suspicious node (AxUS/UNB) that provided data on the definite number of histologically positive nodes. Only two studies primarily performed ultrasound-guided core needle biopsy (CNB) [26, 27]. Both studies defined extensive nodal involvement as pN2-3 disease (Table 2). All studies 
TABLE 2: Summary of studies on US-guided needle biopsy to exclude patients with extensive nodal involvement.

\begin{tabular}{|c|c|c|c|c|c|c|c|}
\hline Study & Year & $\begin{array}{l}\text { No. of } \\
\text { patients }\end{array}$ & $\begin{array}{l}\text { No. (\%) of patients with extensive nodal } \\
\text { involvement }\end{array}$ & $\begin{array}{l}\text { No. of false } \\
\text { negatives }\end{array}$ & $\begin{array}{l}\text { No. of true } \\
\text { negatives }\end{array}$ & $\begin{array}{l}\text { NPV } \\
(\%)\end{array}$ & $\begin{array}{c}\text { FNR } \\
(\%)\end{array}$ \\
\hline \multicolumn{8}{|c|}{ Studies in which extensive nodal involvement was defined as pN2-3 } \\
\hline \multicolumn{8}{|c|}{ US/FNAC } \\
\hline Gipponi et al. [34] & 2016 & 400 & $42(10.5 \%)$ & 15 & 329 & 96 & 36 \\
\hline $\begin{array}{l}\text { Wely van et al. } \\
\text { [14] }\end{array}$ & 2013 & 1448 & $178(12.3 \%)$ & 99 & 1154 & 92 & 56 \\
\hline \multicolumn{8}{|l|}{ US/CNB } \\
\hline $\begin{array}{l}\text { Nijnatten van } \\
\text { et al. [27] }\end{array}$ & 2016 & 377 & $16(4.2 \%)$ & 5 & 339 & 99 & 31 \\
\hline $\begin{array}{l}\text { Schipper et al. } \\
\text { [26] }\end{array}$ & 2013 & 577 & $47(8.1 \%)$ & 23 & 499 & 94 & 49 \\
\hline \multicolumn{8}{|c|}{$\begin{array}{l}\text { Studies in which extensive nodal involvement was defined as } \geq 3 \text { positive nodes } \\
\text { US/FNAC }\end{array}$} \\
\hline Barco et al. [16] & 2016 & 1506 & $200(13.3 \%)$ & 74 & 1223 & 94 & 37 \\
\hline Farrell et al. [25] & 2015 & 322 & $29(9.0 \%)$ & 9 & 281 & 97 & 31 \\
\hline Hieken et al. [17] & 2013 & 906 & $76(8.4 \%)$ & 34 & 790 & 96 & 45 \\
\hline Kramer et al. [19] & 2016 & 2130 & $248(11.6 \%)$ & 137 & 1802 & 93 & 55 \\
\hline Wallis et al. [35] & 2018 & 769 & $36(4.7 \%)$ & 21 & 716 & 97 & 58 \\
\hline Zhu et al. [28] & 2016 & 445 & $84(18.9 \%)$ & 13 & 314 & 96 & 15 \\
\hline Mean & & & & & & 95 & 43 \\
\hline
\end{tabular}

US/FNAC = axillary ultrasonography followed by fine-needle aspiration cytology of suspicious nodes; US/CNB = axillary ultrasonography followed by core needle biopsy of suspicious nodes; no. of false negatives = number of patients with normal/negative test but histologically extensive nodal involvement; no. of true negatives $=$ number of patients with normal/negative test and histologically no/limited nodal involvement; NPV = negative predictive value; FNR $=$ falsenegative rate.

that defined extensive nodal involvement as $\geq 3$ positive nodes performed ultrasound-guided fine-needle aspiration cytology (FNAC). In these studies, the FNR of AxUS/FNAC ranges from 15 to $58 \%$ (mean $43 \%$ ). Thus, on average, $43 \%$ of patients with $\geq 3$ positive nodes had a negative AxUS/FNAC (either AxUS- or AxUS+/FNAC-). The NPV of a negative AxUS/FNAC to exclude $\geq 3$ positive nodes ranges from 93 to $97 \%$ (mean 95\%). Hence, the chance of $\geq 3$ positive nodes is approximately $5 \%$ in case of a negative AxUS/FNAC (Table 2) [16, 17, 19, 25, 28, 35].

\subsubsection{Identifying Patients with Extensive Nodal Involvement.} Many studies evaluated the role of US/UNB in selecting patients with extensive nodal disease. Most of these studies evaluated axillary tumor burden amongst different breast cancer patient subgroups (UNB-positive versus SNB-positive patients). Recently, three meta-analyses on this subject were published [36-38]. Houssami and Turner [37] estimated that, amongst patients with positive nodes, the odds ratio for high nodal disease burden ( $\geq 4$ positive nodes) was 4.38 (95\% CI 3.13-6.13) for a positive UNB versus a negative UNB [37]. Wely van et al. [36] compared the number of patients with histological N1 and N2-3 disease between patients with a positive $\mathrm{UNB}(\mathrm{UNB}+)$ and patients with a negative UNB but positive SNB (UNB-/SNB+). The preferred method of biopsy was FNAC in about $90 \%$ of patients. Significantly more patients in the UNB+ group had $\mathrm{pN} 2-3$ disease than in the UNB-/SNB+ group $(P<0.001)$, that is, $56.0 \%$ (298 of 532) versus $23.8 \%$ (59 of 248) [36]. Ahmed et al. [38] compared the number of patients with $\leq 2$ metastatic nodes and $\geq 3$ metastatic nodes, in addition to only considering macrometastases. They concluded that significantly more patients in the UNB+ group had $\geq 3$ metastatic nodes compared to the $\mathrm{SNB}+$ group (odds ratio 5.95, 95\% CI 5.80-6.11). The mean number of macrometastatically involved nodes was 2.9 (standard error 0.2 ) for the UNB+ and 1.6 (standard error 0.2) for the SNB+ group. Finally, cumulative probability identified that $56.8 \%$ of $\mathrm{UNB}+$ patients and $21.1 \%$ of SNB+ patients had $\geq 3$ macrometastatic nodes [38]. In short, the mean number of positive nodes is significantly higher in UNB+ patients compared to SNB-positive patients. Approximately 56\% of patients with their positive nodes identified by UNB will ultimately have extensive nodal involvement.

Ideally, these UNB+ patients with extensive nodal involvement can be distinguished from UNB+ patients with limited nodal involvement preoperatively. A few recent studies addressed this topic and compared clinical, radiological, and pathological features between these two UNB+ subgroups $[30,33,39]$. Features that were significantly associated with having extensive nodal involvement at final pathology in UNB+ patients were as follows: larger tumor size $[30,39]$, lobular histology [30, 39], a higher grade of lymphovascular invasion [39], maximum cortical thickness of the most suspicious node larger than 4.0 millimeters [33], and having more than one suspicious lymph node on AxUS $[30,33,39]$. For UNB+ patients with both primary tumor size on imaging $\leq 2$ centimeters and one abnormal node on AxUS, only $27 \%$ had N2-3 disease at final pathology $(P=0.007)$ [30].

\subsection{Magnetic Resonance Imaging}

3.3.1. Excluding Extensive Nodal Involvement. In total, six studies evaluating the accuracy of MRI provided data on the total number of (histologically) positive nodes (Table 3). All studies used a MRI system with a coil covering breast and 
TABLE 3: Summary of studies on MRI to exclude patients with extensive nodal involvement.

\begin{tabular}{|c|c|c|c|c|c|c|c|c|}
\hline Study & Year & $\begin{array}{c}\text { Field } \\
\text { strength }\end{array}$ & $\begin{array}{l}\text { No. of } \\
\text { patients }\end{array}$ & $\begin{array}{l}\text { No. (\%) of patients with extensive } \\
\text { nodal involvement }\end{array}$ & $\begin{array}{l}\text { No. of false } \\
\text { negatives }\end{array}$ & $\begin{array}{l}\text { No. of true } \\
\text { negatives }\end{array}$ & $\begin{array}{l}\text { NPV } \\
(\%)\end{array}$ & $\begin{array}{c}\text { FNR } \\
(\%)\end{array}$ \\
\hline \multicolumn{9}{|c|}{ Studies in which extensive nodal involvement was defined as pN2-3 } \\
\hline \multicolumn{9}{|c|}{ Unenhanced MRI (T1w/T2w) } \\
\hline \multirow{2}{*}{$\begin{array}{l}\text { Nijnatten van } \\
\text { et al. [27] }\end{array}$} & 2016 & $1.5 \mathrm{~T}$ & 377 & $16(4.2 \%)$ & 3 & 318 & 99 & 19 \\
\hline & 2016 & $1.5 \mathrm{~T}$ & 377 & $16(4.2 \%)$ & 2 & 297 & 99 & 13 \\
\hline \multicolumn{9}{|l|}{ DCE-MRI } \\
\hline Hwang et al. [40] & 2013 & $1.5 \mathrm{~T}$ & 349 & $18(5.2 \%)$ & 4 & 272 & 99 & 22 \\
\hline Hyun et al. [41] & 2016 & $3.0 \mathrm{~T}$ & 310 & $12(3.9 \%)$ & 1 & 256 & 99.6 & 8 \\
\hline \multicolumn{9}{|c|}{ Studies in which extensive nodal involvement was defined as $\geq 3$ positive nodes } \\
\hline \multicolumn{9}{|c|}{ Unenhanced MRI (T1w/T2w) } \\
\hline Barco et al. [16] & 2016 & $1.5 \mathrm{~T}$ & 1351 & $182(13.5 \%)$ & 100 & 1066 & 91 & 55 \\
\hline \multicolumn{9}{|l|}{ DCE-MRI } \\
\hline Hieken et al. [17] & 2013 & $1.5 \mathrm{~T}$ & 505 & $52(10.3 \%)$ & 10 & 327 & 97 & 19 \\
\hline Kim et al. [18] & 2019 & $3.0 \mathrm{~T}$ & 256 & $17(6.6 \%)$ & 2 & 179 & 99 & 12 \\
\hline
\end{tabular}

MRI = magnetic resonance imaging; DCE-MRI = dynamic contrast-enhanced MRI (using gadolinium-based contrast agents); No. of false negatives = number of patients with normal/negative MRI but histologically extensive nodal involvement; no. of true negatives = number of patients with normal/negative MRI and histologically no/limited nodal involvement; NPV = negative predictive value; FNR = false-negative rate.

axilla. Three studies defined extensive nodal involvement as $\geq 3$ positive nodes. Two of these three studies performed dynamic contrast-enhanced MRI (DCE-MRI) with gadolinium-based contrast agents $[17,18]$. One of these studies performed unenhanced MRI [16]. Accuracy of DCE-MRI to exclude $\geq 3$ positive nodes seems to be better than unenhanced MRI. The FNR of DCE-MRI ranged from 12 to $19 \%$ (mean 17\%) and NPV ranged from 97 to 99\% (mean 98\%) (Table 3) $[17,18]$.

\subsubsection{Identifying Patients with Extensive Nodal Involvement.} Only few studies examined whether MRI could be used to distinguish between limited and extensive nodal involvement. Kim et al. [18] compared clinical, radiological, and pathological features between early breast cancer patients with $\leq 2$ positive nodes and patients with $\geq 3$ positive nodes. They performed DCE-MRI with gadolinium-based contrast agents (field strength of $3.0 \mathrm{~T}$ ). In multivariate analysis, a higher number of suspicious lymph nodes on MRI was significantly associated with the presence of $\geq 3$ positive nodes on final pathology ( 2 suspicious nodes, OR 69.0, $P=0.001 ; \geq 3$ suspicious nodes, $\mathrm{OR}=93.55, P<0.001)$. In patients with no or only one suspicious node on MRI, the percentage of patients with $\geq 3$ positive nodes on final pathology was $1.8 \%$ ( 4 of 225). In contrast, in patients with two or more suspicious nodes on MRI, the percentage of patients with $\geq 3$ positive nodes on final pathology was $41.9 \%$ (13 of 31) $(P<0.001)$. When using this threshold of two suspicious nodes on MRI, 4 of 17 (23.5\%) patients with $\geq 3$ positive nodes on final pathology would have been missed. Cortical morphologic changes of the most suspicious node on MRI were not independently associated with $\geq 3$ positive nodes on final pathology in the series of Kim et al. [18]. Hieken et al. [17] performed a similar study. They differentiated between no, only one, and more than one suspicious lymph node on magnetic resonance images. Images were obtained by DCEMRI (1.5 T) using gadolinium in 505 breast cancer patients. If no, only one, or more than one suspicious node was seen on MRI, the percentage of patients with $\geq 3$ positive nodes on final pathology was $3.0 \%$ (10 of 337), 15.1\% (11 of 73), and $32.6 \%$ (31 of 95$)$, respectively $(P=0.008)$ [17]. When using a threshold of two suspicious nodes on MRI, $32.6 \%$ of patients had $\geq 3$ positive nodes on final pathology. At this threshold, $40.4 \%$ ( 21 of 52 ) of patients with $\geq 3$ positive nodes on final pathology would have been missed. Next, Hyun et al. [41] performed DCE-MRI (3.0 T) using gadolinium in 310 breast cancer patients. They differentiated between $\mathrm{cN} 0, \mathrm{cN} 1$, and cN2-3 based on MRI. If no abnormal nodes were identified (cN0), $0.4 \%$ (1 of 257) was ultimately shown to have pN2-3 disease by histopathology. 45 cases were staged as cN1, of which 7 were pN2-3 (15.6\%). Finally, 8 cases were staged as cN2-3, of which 4 were pN2-3 (50\%) [41]. A similar study was performed by Nijnatten van et al. [27]. They evaluated the axillary regions of 377 breast cancer patients on unenhanced T2-weighted sequences. Their results were virtually identical to the results of Hyun et al. [41].

At last, two studies analyzed if MRI can be used to distinguish $\mathrm{UNB}+$ patients with extensive nodal involvement from UNB+ patients with limited nodal involvement. Hieken et al. [17] concluded that the chance of $\geq 3$ positive nodes was significantly higher in UNB+ patients with more than one suspicious node on MRI compared to patients with only one suspicious node on MRI (67.6\% vs. $30.3 \%, P=0.005)$ [17]. In a study of Pilewskie et al. [39], a trend was shown that the rate of $\geq 3$ positive nodes was higher in $\mathrm{UNB}+$ patients with more than one suspicious node on MRI compared to only one or no suspicious nodes $(P=0.083)$.

\subsection{F-FDG PET/CT}

3.4.1. Excluding Extensive Nodal Involvement. The combination of metabolic and morphologic data can be obtained with integrated 18F-FDG PET/CT systems. Only two studies that performed 18F-FDG PET/CT reported the total number of histologically positive nodes (Table 4). One of these studies defined extensive nodal involvement as $\geq 3$ positive 
TABLE 4: Summary of studies on 18F-FDG PET/CT to exclude patients with extensive nodal involvement.

\begin{tabular}{|c|c|c|c|c|c|c|c|}
\hline Study & Year & $\begin{array}{c}\text { No. of } \\
\text { patients }\end{array}$ & $\begin{array}{c}\text { No. (\%) of patients with extensive nodal } \\
\text { involvement }\end{array}$ & $\begin{array}{l}\text { No. of false } \\
\text { negatives }\end{array}$ & $\begin{array}{l}\text { No. of true } \\
\text { negatives }\end{array}$ & $\begin{array}{l}\text { NPV } \\
(\%)\end{array}$ & $\begin{array}{c}\text { FNR } \\
(\%)\end{array}$ \\
\hline \multicolumn{8}{|c|}{ Study in which extensive nodal involvement was defined as pN2-3 } \\
\hline $\begin{array}{l}\text { Hwang et al. } \\
\text { [40] }\end{array}$ & 2013 & 349 & $18(5.2 \%)$ & 5 & 288 & 98 & 28 \\
\hline \multicolumn{8}{|c|}{ Study in which extensive nodal involvement was defined as $\geq 3$ positive nodes } \\
\hline Ahn et al. [32] & 2017 & 364 & $43(11.8 \%)$ & 9 & 250 & 97 & 21 \\
\hline
\end{tabular}

nodes [32]. In this study, $21 \%$ of patients with $\geq 3$ positive nodes had a negative (axillary) PET/CT. The NPV of a negative (axillary) PET/CT to exclude $\geq 3$ positive nodes was $97 \%$ in this study [32]. The study that defined extensive nodal involvement as pN2-3 had similar results: FNR 28\% and NPV 98\% [40].

\subsubsection{Identifying Patients with Extensive Nodal Involvement.} Several studies were published on axillary tumor burden according to PET/CT scans in newly diagnosed breast cancer patients with $\mathrm{N}+$ disease [6]. However, patients were treated with neoadjuvant chemotherapy in these studies. No single study on locoregional staging with PET/ CT compared the number of suspicious axillary lymph nodes on PET/CT with pathological nodal burden without systemic therapy in between. Therefore, only circumstantial evidence is available to answer the question if $\mathrm{PET} / \mathrm{CT}$ is helpful in predicting the extent of axillary nodal involvement.

First, the percentages of patients with extensive nodal involvement were $23.2 \%$ [40], 32.4\% [32], and 64.0\% [42] in three studies when PET/CT was positive for axillary nodal involvement. These newly diagnosed breast cancer patients all had clinically negative axillae.

Fuster et al. [43] performed PET/CT in sixty consecutive patients with primary breast carcinomas larger than three centimeters. Axillary lymph node metastases were confirmed in 20 of 52 patients with ALND. In these 20 patients, 84 of 315 nodes were histologically confirmed to contain metastases. On a lymph node count, PET/CT detected 24 of these 84 metastatic lymph nodes. Hence, the best lesion-based sensitivity in their study was $28.6 \%$. Unfortunately, the authors did not differentiate between micro- and macrometastases [43]. Heusner et al. [44] performed a similar study. They analyzed FDG avidity of all lymph nodes $\geq 5 \mathrm{~mm}$ that were noted on CT. Any focus which could be mapped to a lymph node and was considered elevated above normal was rated as positive for metastasis. PET/CT results were correlated to histopathological findings of ALND. Of 61 patients, 24 had positive nodes on final histopathology (150 positive nodes in total). In 14 true-positive PET/CT scans, 60 suspicious lymph nodes were detected. When considering these 60 lymph nodes as truly positive nodes, their best lesion-based sensitivity was $41 \%$ [44]. However, no node-to-node correlation between avid nodes on PET/ $\mathrm{CT}$ and histologically metastatic nodes was performed in these studies. Theoretically, PET-positive nodes may have been false-positive due to inflammation for instance. Thus, the true lesion-based sensitivity for $18 \mathrm{~F}$ FDG PET/CT may be lower than the percentages reported in these two studies. In short, 18F-FDG PET/CT highly underestimates the number of metastatic axillary lymph nodes.

\section{Discussion}

Treatment of clinical T1-2N0 breast cancer patients with one or two metastatic sentinel nodes has changed after publication of the ACOSOG Z0011 [1], IBCSG 23-01 [2], and AATRM 048/13/2000 [3] trials. Omitting completion ALND in these patients did not compromise overall survival nor regional disease control. Only patients who were treated by breast-conserving surgery, whole-breast irradiation, and adjuvant systemic therapy were included in these trials. Excluding extensive nodal involvement rather than detecting occult node-positive disease has become increasingly important since then. Ideally, this task is fulfilled by preoperative axillary imaging modalities. Therefore, we questioned if negative results of AxUS, AxUS/UNB, MRI, and PET/CT can exclude the presence of extensive nodal involvement in newly diagnosed breast cancer patients. In some studies that we reviewed, the number of patients with $\geq 3$ positive nodes was described. In other studies, the number of patients with pN1 (1 to 3 positive nodes) and $\mathrm{pN} 2-3$ ( $\geq 4$ positive nodes) was described. We were particularly interested in excluding the presence of $\geq 3$ positive nodes. When the presence of $\geq 3$ positive nodes can be excluded preoperatively in breast cancer patients that meet the ACOSOG Z0011 eligibility criteria, surgically staging the axilla (by SNB) is redundant in these patients.

When applied to exclude extensive nodal involvement, the ultimate axillary staging modality is featured by a NPV of $100 \%$ and a FNR of $0 \%$. Only ALND approaches these requirements. Even SNB is featured by a false-negative rate of $9.8 \%$ in the largest randomized clinical trial comparing SNB with ALND in patients with clinically node-negative breast cancer [45]. Using SNB as 
a reference standard is therefore a drawback of this review article. In the control (cALND) arm of the ACOSOG Z0011 trial, $21.0 \%$ had $\geq 3$ positive nodes. Despite this high rate of extensive nodal involvement, there was a very low rate of axillary recurrences in the no-ALND arm (1.6\% after 5 years) [1]. This discrepancy was probably due to the effects of adjuvant systemic therapy and whole-breast irradiation, which eliminated residual axillary metastases. In our opinion, the FNRs of preoperative axillary staging methods that are applied to exclude $\geq 3$ positive nodes (in patients who meet the ACOSOG Z0011 eligibility criteria) should not exceed this rate of $21.0 \%$.

In Table 5, NPVs and FNRs of all preoperative axillary imaging modalities to exclude $\geq 3$ positive nodes are summarized. NPVs of all modalities to exclude $\geq 3$ positive nodes are very high (mean NPVs of all modalities approximately $95 \%)$. These very high NPVs can (partially) be explained by the low prevalence of $\geq 3$ positive nodes because NPV is inversely related to prevalence. Since FNR is intrinsic to a test, the FNR might be more helpful to determine which imaging modality might best be used to exclude $\geq 3$ positive nodes.

AxUS and AxUS/UNB are the most widely studied preoperative axillary imaging modalities. FNRs of both negative AxUS and negative AxUS/FNAC (either AxUS- or AxUS+ FNAC-) were well above the arbitrarily decided maximum FNR of $21 \%$. Thus, when relying on negative AxUS or negative AxUS/FNAC results, too many patients with $\geq 3$ positive nodes would be missed and would not be properly treated. This could negatively influence the number of locoregional recurrences and prognosis [6-8]. AxUS/ FNAC performs worse than AxUS in excluding $\geq 3$ positive nodes. This worse FNR of AxUS/FNAC to exclude $\geq 3$ positive nodes can be explained by the fact that the falsenegative results of FNAC are added to the false-negative results of AxUS.

Evidence regarding the diagnostic performance of both MRI and PET/CT in excluding $\geq 3$ positive nodes is very scarce. DCE-MRI with gadolinium-based contrast agents seems to perform better in excluding $\geq 3$ positive nodes than nonenhanced MRI albeit DCE-MRI showed less promising results in a previous systematic review on the role of MRI in axillary lymph node imaging [46]. In both studies that evaluated DCE-MRI with gadolinium-based contrast agents, the FNR of a negative MRI to exclude $\geq 3$ positive nodes was lower than $21 \%$. The same holds for PET/CT. Only one PET/CT study met our inclusion criteria, and in this study, the FNR of a negative PET/CT to exclude $\geq 3$ positive nodes was $20.9 \%$. Hence, both negative $\mathrm{PET} / \mathrm{CT}$ and negative DCE-MRI (with gadolinium-based contrast agents) seem promising in excluding $\geq 3$ positive nodes. However, this conclusion is based on only one PET/ CT study and two DCE-MRI studies. Before we can rely on these diagnostic modalities in excluding $\geq 3$ positive nodes, larger studies should be performed to confirm these results.
Our second aim was to evaluate whether these preoperative axillary imaging modalities can accurately distinguish patients with extensive nodal involvement from patients with no or only limited axillary nodal involvement. In short, none of the investigated preoperative axillary imaging modalities can. A higher number of suspicious lymph nodes on AxUS and MRI are significantly associated with extensive nodal involvement. However, the most optimal cutoff (e.g., $\geq 2$ suspicious nodes on AxUS or MRI) to distinguish between limited and extensive nodal involvement has not been determined yet. With rising cutoff values, positive predictive values to predict extensive nodal involvement will rise, but false-negative rates will rise as well (more patients with extensive nodal involvement will be missed). Therefore, the ideal cutoff values may not exist. Mathematical models (nomograms, scores, and prediction rules) combining clinical, pathological, and radiological parameters may be more useful to estimate the chance of extensive nodal involvement in patients with suspicious nodes on AxUS or MRI and in UNB+ patients. Development of these models should be subject for future studies.

Currently, either excluding or identifying extensive nodal involvement in breast cancer patients is of great importance for reasons described above. However, it could be argued that the role of axillary staging will diminish in the near future. In the NSABP B-04 trial, clinically node-negative breast cancer patients were randomized for mastectomy, mastectomy with ALND, or mastectomy with axillary radiotherapy in the 1970s. About $40 \%$ of patients in the ALND group had pathological confirmation of tumor-positive axillary lymph nodes. However, less than half of these patients (18.6\%) had clinically apparent ipsilateral nodal metastases during 25 years of follow-up. None of these patients was treated with systemic therapy or axillary radiotherapy [47]. This discrepancy between axillary recurrences in the no-ALND group and the rate of nonsentinel node metastases in the ALND group was also shown in the ACOSOG Z0011 [1] and IBCSG 23-01 trials [2]. In these latter trials, systemic therapy and radiotherapy have contributed to this discrepancy since almost all patients were treated with systemic therapy and some form of radiotherapy. Even more important, disease-free survival and overall survival were not affected by omitting ALND in any of these trials. Hence, leaving positive axillary nodes unremoved might well not be that big a problem, particularly because the majority of patients are nowadays treated with adjuvant systemic therapy that is increasingly more effective. The current FNR of $31 \%$ of a negative AxUS to exclude extensive nodal involvement might therefore be acceptable in the future. The long-term results of randomized clinical trials in which SNB is omitted and axillary staging is performed exclusively by AxUS (SOUND [4], BOOG 2013-08 [5], and INSEMA) might provide us with some answers. 
TABLE 5: Summary of accuracy of preoperative axillary imaging modalities to exclude patients with $\geq 3$ positive nodes.

\begin{tabular}{|c|c|c|c|c|c|}
\hline Staging modality & No. of studies & Total no. of patients & Prevalence of extensive nodal involvement (mean) & NPV (mean) & FNR (mean) \\
\hline AxUS & 8 & 12.143 & $6.1-18.1(12.1)$ & $92-98(95)$ & $30-37(34)$ \\
\hline US/FNAC & 6 & 6.078 & $4.7-18.9(11.1)$ & 93-97 (95) & $15-58(43)$ \\
\hline MRI & 3 & 2.112 & $6.6-13.5(11.9 \%)$ & $91-99(93)$ & $12-55(45)$ \\
\hline Unenhanced MRI & 1 & 1.351 & 13.5 & 91 & 55 \\
\hline DCE-MRI & 2 & 761 & $6.6-10.3(9.1)$ & $97-99(98)$ & $12-19(17)$ \\
\hline $\mathrm{PET} / \mathrm{CT}$ & 1 & 364 & 11.8 & 97 & 21 \\
\hline
\end{tabular}

No. $=$ number; FNR $=$ false-negative rate; NPV = Negative Predictive Value; AxUS = Axillary Ultrasonography; US/FNAC = AxUS followed by fine-needle aspiration cytology of suspicious node; MRI = Magnetic Resonance Imaging; DCE = Dynamic Contrast Enhanced; PET = Positron Emission Tomography; $\mathrm{PET} / \mathrm{CT}=$ combined PET and Computed Tomography.

\section{Conclusion}

Currently, there is no preoperative axillary imaging modality that can neither identify nor exclude breast cancer patients with extensive nodal involvement accurately. Both negative PET/CT and negative DCE-MRI scans (with gadoliniumbased contrast agents) are promising in excluding $\geq 3$ positive nodes in breast cancer patients. Larger studies should be performed to strengthen this conclusion. False-negative rates of AxUS and AxUS/FNAC are too high to rely on negative results of these modalities in excluding $\geq 3$ positive nodes. However, with increasingly more effective (neo) adjuvant therapy, these current false-negative rates might be acceptable in the future.

\section{Conflicts of Interest}

The authors declare that they have no conflicts of interest.

\section{References}

[1] A. E. Giuliano, K. K. Hunt, K. V. Ballman et al., “Axillary dissection vs. no axillary dissection in women with invasive breast cancer and sentinel node metastasis; a randomized clinical trial," JAMA, vol. 305, no. 6, Article ID 569e75, 2011.

[2] V. Galimberti, B. F. Cole, S. Zurrida et al., "Axillary dissection versus no axillary dissection in patients with sentinel-node micrometastases (IBCSG 23-01): a phase 3 randomised controlled trial," Lancet Oncology, vol. 14, no. 4, pp. 297-305, 2013.

[3] M. Solá, J. A. Alberro, M. Fraile et al., "Complete axillary lymph node dissection versus clinical follow-up in breast cancer patients with sentinel node micrometastasis: final results from the multicenter clinical trial AATRM 048/13/2000," Annals of Surgical Oncology, vol. 20, no. 1, pp. 120-127, 2013.

[4] O. Gentilini and U. Veronesi, "Abandoning sentinel lymph node biopsy in early breast cancer? A new trial in progress at the European Institute of Oncology of Milan (SOUND: sentinel node vs observation after axillary ultrasound)," The Breast, vol. 21, no. 5, pp. 678-681, 2012.

[5] L. M. Roozendaal van, M. L. G. Vane, T. Dalen van et al., "Clinically node negative breast cancer patients undergoing breast conserving therapy, sentinel lymph node procedure versus follow-up: a Dutch randomized controlled multicentre trial (BOOG 2013-08)," BMC Cancer, vol. 17, no. 1, p. 459, 2017.

[6] B. B. Koolen, R. A. Valdés Olmos, W. V. Vogel et al., "Prechemotherapy 18F-FDG PET/CT upstages nodal stage in stage II-III breast cancer patients treated with neoadjuvant chemotherapy," Breast Cancer Research and Treatment, vol. 141, no. 2, pp. 249-254, 2013.

[7] A. Recht, E. A. Comen, R. E. Fine et al., "Postmastectomy radiotherapy: an American society of clinical oncology, American society for radiation oncology, and society of surgical oncology focused guideline update," Journal of Clinical Oncology, vol. 34, no. 36, pp. 4431-4442, 2016.

[8] L. L. Frasier, S. Holden, T. Holden et al., "Temporal trends in postmastectomy radiation therapy and breast reconstruction associated with changes in national comprehensive cancer network guidelines," JAMA Oncology, vol. 2, no. 1, pp. 95-101, 2016.

[9] H. Abe, D. Schacht, C. A. Sennett, G. M. Newstead, and R. A. Schmidt, "Utility of preoperative ultrasound for predicting $\mathrm{pN} 2$ or higher stage axillary lymph node involvement in patients with newly diagnosed breast cancer," American Journal of Roentgenology, vol. 200, no. 3, pp. 696-702, 2013.

[10] S. J. Amonkar, E. Oates, L. McLean, and S. Nicholson, "Preoperative staging of the axilla in primary breast cancer. By redefining the abnormal appearing node can we reduce investigations without affecting overall treatment?," The Breast, vol. 22, no. 6, pp. 1114-1118, 2013.

[11] R. S. Jackson, C. Mylander, M. Rosman et al., "Normal axillary ultrasound excludes heavy nodal disease burden in patients with breast cancer," Annals of Surgical Oncology, vol. 22, no. 10, pp. 3289-3295, 2015.

[12] Y. Kijima, H. Yoshinaka, M. Hirata et al., "Number of axillary lymph node metastases determined by preoperative ultrasound is related to prognosis in patients with breast cancer," Cancers, vol. 2, no. 1, pp. 20-31, 2010.

[13] Q. Liu, P. Xing, H. Dong, T. Zhao, and F. Jin, "Preoperative assessment of axillary lymph node status in breast cancer patients by ultrasonography combined with mammography," Medicine, vol. 97, p. 30, 2018.

[14] B. J. Wely van, J. H. W. Wilt de, P. J. C. Schout et al., "Ultrasound-guided fine-needle aspiration of suspicious nodes in breast cancer patients; selecting patients with extensive nodal involvement," Breast Cancer Research and Treatment, vol. 140, pp. 113-118, 2013.

[15] Y.-N. Zhang, C.-J. Wang, Y. Xu et al., "Sensitivity, specificity and accuracy of ultrasound in diagnosis of breast cancer metastasis to the axillary lymph nodes in Chinese patients," Ultrasound in Medicine \& Biology, vol. 41, no. 7, pp. 18351841, 2015.

[16] I. Barco, C. Chabrera, A. García-Fernández et al., "Role of axillary ultrasound, magnetic resonance imaging, and ultrasound-guided fine-needle aspiration biopsy in the preoperative triage of breast cancer patients," Clinical and Translational Oncology, vol. 19, no. 6, pp. 704-710, 2016.

[17] T. J. Hieken, B. C. Trull, J. C. Boughey et al., "Preoperative axillary imaging with percutaneous lymph node biopsy is 
valuable in the contemporary management of patients with breast cancer," Surgery, vol. 154, no. 4, pp. 831-840, 2013.

[18] W. H. Kim, H. J. Kim, S. M. Lee et al., "Prediction of high nodal burden with ultrasound and magnetic resonance imaging in clinically node-negative breast cancer patients," Cancer Imaging, vol. 19, 2019.

[19] G. M. Kramer, M. W. H. Leenders, L. J. Schijf et al., "Is ultrasound-guided fine-needle aspiration cytology of adequate value in detecting breast cancer patients with three or more positive axillary lymph nodes?," Breast Cancer Research and Treatment, vol. 156, no. 2, pp. 271-278, 2016.

[20] B. Lee, A. K. Lim, J. Krell et al., "The efficacy of axillary ultrasound in the detection of nodal metastasis in breast cancer," American Journal of Roentgenology, vol. 200, no. 3, pp. W314-W320, 2013.

[21] G. H. Lim, S. Y. Teo, J. C. Allen, J. P. Chinthala, and L. C. H. Leong, "Determining whether high nodal burden in early breast cancer patients can be predicted preoperatively to avoid sentinel lymph node biopsy," Journal of Breast Cancer, vol. 22, no. 1, pp. 67-76, 2019.

[22] A. M. Moorman, R. L. J. H. Bourez, H. J. Heijmans, and E. A. Kouwenhoven, "Axillary ultrasonography in breast cancer patients helps in identifying patients preoperatively with limited disease of the axilla," Annals of Surgical Oncology, vol. 21, no. 9, pp. 2904-2910, 2014.

[23] E. Morrow, A. Lannigan, J. Doughty et al., "Population-based study of the sensitivity of axillary ultrasound imaging in the preoperative staging of node-positive invasive lobular carcinoma of the breast," British Journal of Surgery, vol. 105, no. 8, pp. 987-995, 2018.

[24] A. S. Caudle, H. M. Kuerer, H. T. Le-Petross et al., "Predicting the extent of nodal disease in early-stage breast cancer," Annals of Surgical Oncology, vol. 21, no. 11, pp. 3440-3447, 2014.

[25] T. P. J. Farrell, N. C. Adams, M. Stenson et al., "The Z0011 trial: is this the end of axillary ultrasound in the pre-operative assessment of breast cancer patients?," European Radiology, vol. 25, no. 9, pp. 2682-2687, 2015.

[26] R. J. Schipper, L. M. van Roozendaal, B. de Vries et al., "Axillary ultrasound for preoperative nodal staging in breast cancer patients: is it of added value?," The Breast, vol. 22, no. 6, pp. 1108-1113, 2013.

[27] T. J. A. Nijnatten van, E. H. Ploumen, R. J. Schipper et al., "Routine use of standard breast MRI compared to axillary ultrasound for differentiating between no, limited and advanced axillary nodal disease in newly diagnosed breast cancer patients," European Journal of Radiology, vol. 85, pp. 22882294, 2016.

[28] Y. Zhu, W. Zhou, J.-Q. Zhou et al., “Axillary staging of earlystage invasive breast cancer by ultrasound-guided fine-needle aspiration cytology," Journal of Ultrasound in Medicine, vol. 35 , no. 5 , pp. $885-893,2016$.

[29] J. del Riego, M. J. Diaz-Ruiz, M. Teixidó et al., “The impact of axillary ultrasound with biopsy in overtreatment of early breast cancer," European Journal of Radiology, vol. 98, pp. 158-164, 2018.

[30] C. K. Harris, H. T. Tran, K. Lee et al., "Positive ultrasoundguided lymph node needle biopsy in breast cancer may not mandate axillary lymph node dissection," Annals of Surgical Oncology, vol. 24, no. 10, pp. 3004-3010, 2017.

[31] X. Wang, L. Chen, Y. Sun, and B. Zhang, "Evaluation of axillary lymph node metastasis burden by preoperative ultrasound in early-stage breast cancer with needle biopsyproven metastasis," Clinical and Translational Oncology, 2019.
[32] S. K. Ahn, M. K. Kim, J. Kim et al., "Can we skip intraoperative evaluation of sentinel lymph nodes? Nomogram predicting involvement of three or more axillary lymph nodes before breast cancer surgery," Cancer Research and Treatment, vol. 49, no. 4, pp. 1088-1096, 2017.

[33] G. H. Lim, V. S. Upadhyaya, H. A. Acosta, J. M. A. Lim, J. C. Allen Jr., and L. C. H. Leong, "Preoperative predictors of high and low axillary nodal burden in Z0011 eligible breast cancer patients with a positive lymph node needle biopsy result," European Journal of Surgical Oncology, vol. 44, no. 7, pp. 945-950, 2018.

[34] M. Gipponi, P. Fregatti, A. Garlaschi et al., "Axillary ultrasound and fine-needle aspiration cytology in the preoperative staging of axillary node metastasis in breast cancer patients," The Breast, vol. 30, pp. 146-150, 2016.

[35] M. G. Wallis, F. Kilburn-Toppin, and S. Taylor-Phillips, "Does preoperative axillary staging lead to overtreatment of women with screen-detected breast cancer?," Clinical Radiology, vol. 73, no. 5, pp. 467-472, 2018.

[36] B. J. Wely van, J. H. W. Wilt de, C. Francissen, S. Teerenstra, and L. J. A. Strobbe, "Meta-analysis of ultrasound-guided biopsy of suspicious axillary lymph nodes in the selection of patients with extensive axillary tumour burden in breast cancer," BJS, vol. 102, pp. 159-168, 2015.

[37] N. Houssami and R. M. Turner, "Staging the axilla in women with breast cancer: the utility of preoperative ultrasoundguided needle biopsy," Cancer Biology \& Medicine, vol. 11, pp. 69-77, 2014.

[38] M. Ahmed, F. Jozsa, R. Baker, I. T. Rubio, J. Benson, and M. Douek, "Meta-analysis of tumour burden in pre-operative axillary ultrasound positive and negative breast cancer patients," Breast Cancer Research and Treatment, vol. 166, no. 2, pp. 329-336, 2017.

[39] M. Pilewskie, S. K. Mautner, M. Stempel, A. Eaton, and M. Morrow, "Does a positive axillary lymph node needle biopsy result predict the need for an axillary lymph node dissection in clinically node-negative breast cancer patients in the ACOSOG Z0011 era?," Annals of Surgical Oncology, vol. 23 , no. 4, pp. 1123-1128, 2016.

[40] S. O. Hwang, S.-W. Lee, H. J. Kim, W. W. Kim, H. Y. Park, and J. H. Jung, "The comparative study of ultrasonography, contrast-enhanced MRI, and18F-FDG PET/CT for detecting axillary lymph node metastasis in T1 breast cancer," Journal of Breast Cancer, vol. 16, no. 3, pp. 315-321, 2013.

[41] S. J. Hyun, E.-K. Kim, H. J. Moon, J. H. Yoon, and M. J. Kim, "Preoperative axillary lymph node evaluation in breast cancer patients by breast magnetic resonance imaging (MRI): can breast MRI exclude advanced nodal disease?," European Radiology, vol. 26, no. 11, pp. 3865-3873, 2016.

[42] Y. Nakano, M. Noguchi, M. Yokoi-Noguchi et al., "The roles of 18F-FDG-PET/CT and US-guided FNAC in assessment of axillary nodal metastases in breast cancer patients," Breast Cancer, vol. 24, no. 1, pp. 121-127, 2017.

[43] D. Fuster, J. Duch, P. Paredes et al., "Preoperative staging of large primary breast cancer with $[18 \mathrm{~F}]$ Fluorodeoxyglucose positron emission tomography/computed tomography compared with conventional imaging procedures," Journal of Clinical Oncology, vol. 26, no. 29, pp. 4746-4751, 2008.

[44] T. A. Heusner, S. Kuemmel, S. Hahn et al., "Diagnostic value of full-dose FDG PET/CT for axillary lymph node staging in breast cancer patients," European Journal of Nuclear Medicine and Molecular Imaging, vol. 36, no. 10, pp. 1543-1550, 2009.

[45] D. N. Krag, S. J. Anderson, T. B. Julian et al., "Technical outcomes of sentinel-lymph-node resection and conventional 
axillary-lymph-node dissection in patients with clinically node-negative breast cancer: results from the NSABP B-32 randomised phase III trial," The Lancet Oncology, vol. 8, no. 10, pp. 881-888, 2007.

[46] N. Avril, J. Dose, F. Janicke et al., “Assessment of axillary lymph node involvement in breast cancer patients with positron emission tomography using radiolabeled 2-(Fluorine-18)-fluoro-2-deoxy-D-glucose," JNCI Journal of the National Cancer Institute, vol. 88, no. 17, pp. 1204-1209, 1996.

[47] B. Fisher, J.-H. Jeong, S. Anderson, J. Bryant, E. R. Fisher, and N. Wolmark, "Twenty-five-year follow-up of a randomized trial comparing radical mastectomy, total mastectomy, and total mastectomy followed by irradiation," New England Journal of Medicine, vol. 347, no. 8, pp. 567-575, 2002. 


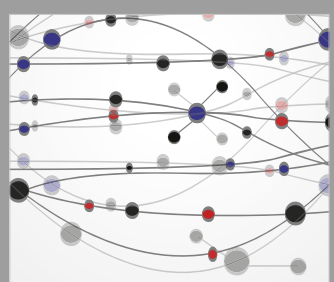

The Scientific World Journal
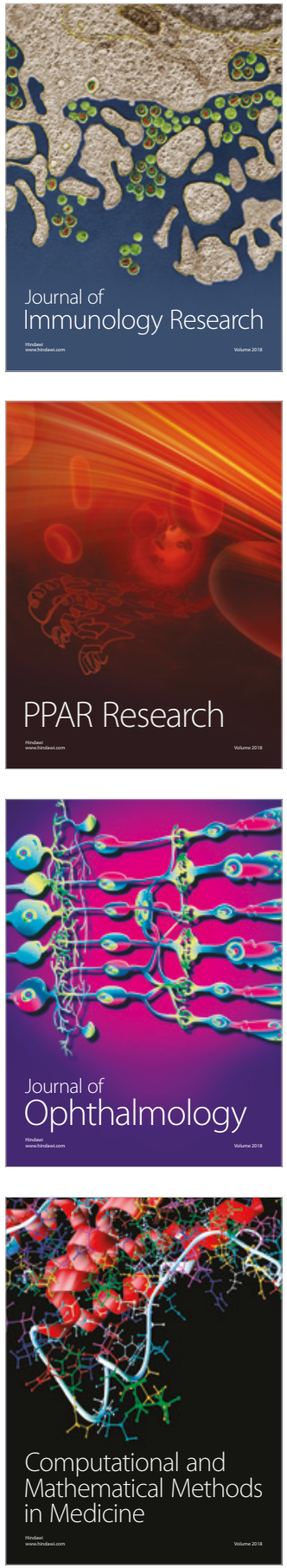

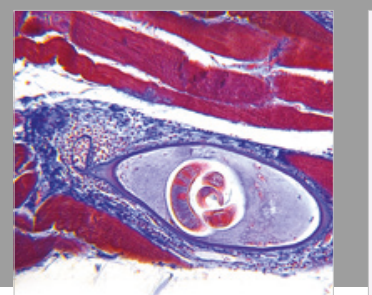

Gastroenterology Research and Practice

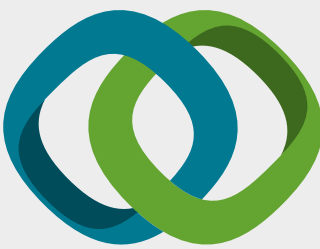

\section{Hindawi}

Submit your manuscripts at

www.hindawi.com
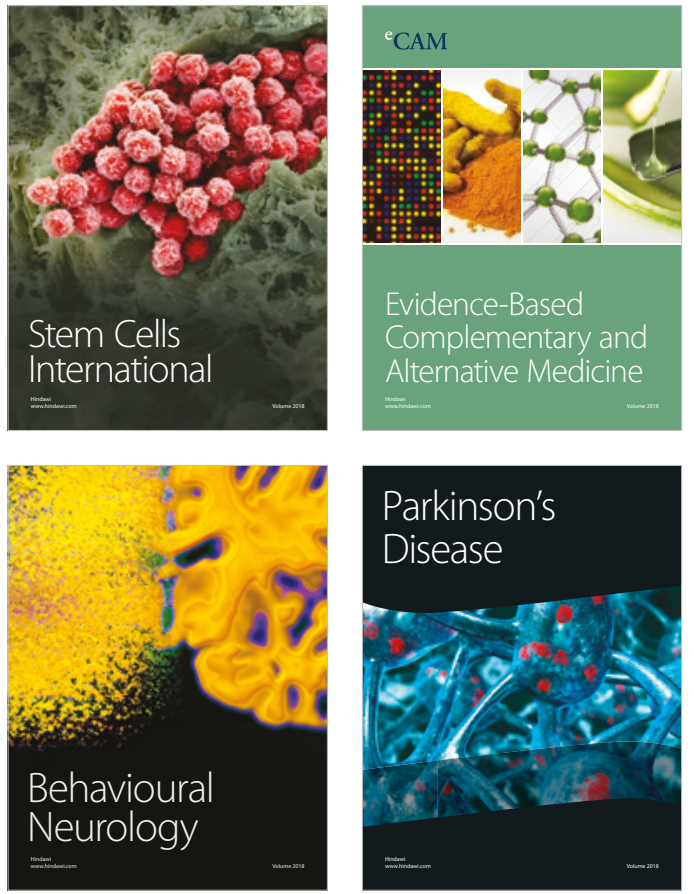

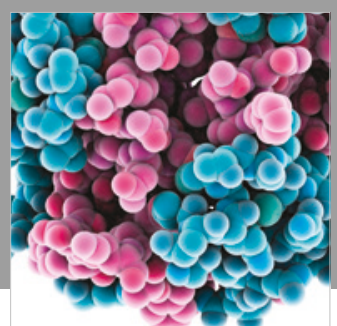

ournal of

Diabetes Research

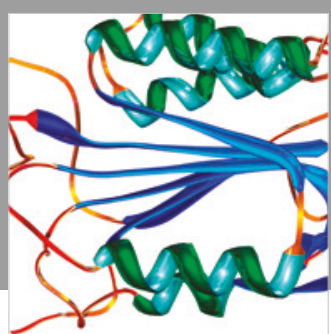

Disease Markers
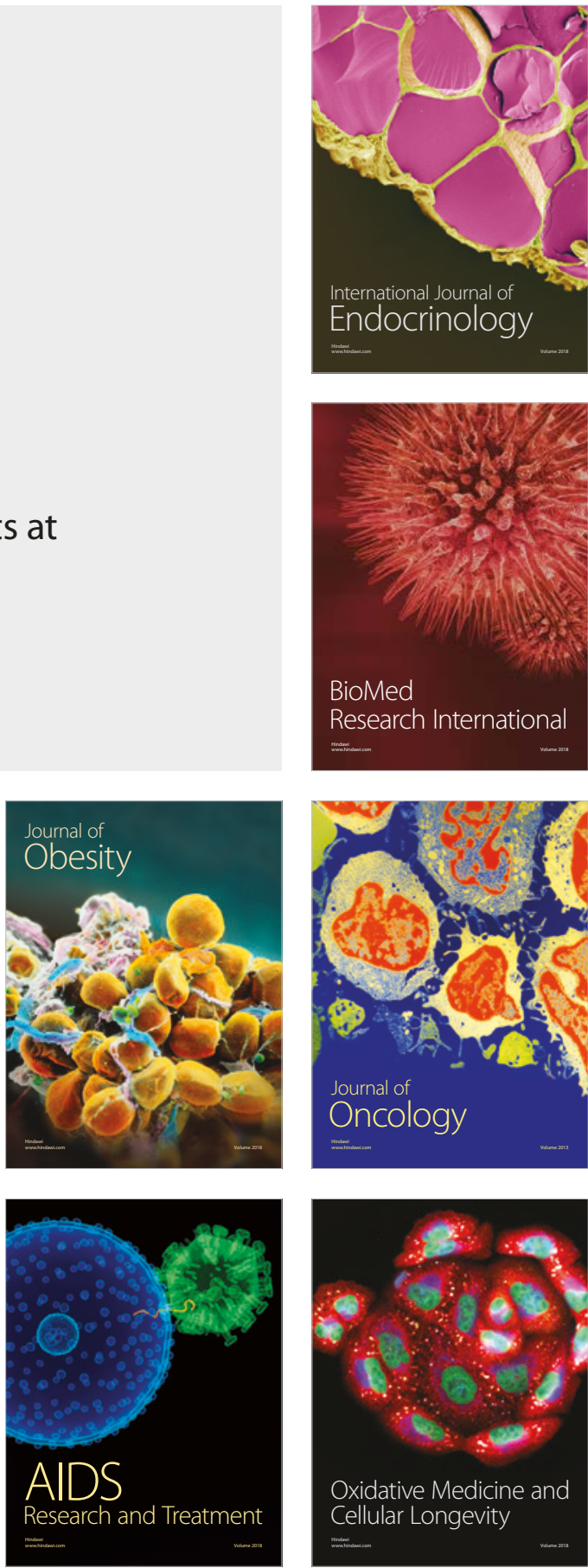